\title{
Cognitive activity and students' coping strategies
}

\author{
S. Krivoschekov ${ }^{1 *}$, E. Vergunov ${ }^{1}$, N. Balioz ${ }^{1}$, K. Soloveva ${ }^{2}$, E. Bobrovskaya $^{2}$ \\ ${ }^{1}$ Scientific Research Institute of Physiology and Basic Medicine, Novosibirsk, Russia \\ ${ }^{2}$ Novosibirsk State University of Economics and Management, Novosibirsk, Russia \\ *e-mail:krivosch@physiol.ru
}

Key words: allostasis, coping, cognitive activity, educational activity, first year students

Motivation and Aim: Various aspects of the allostatic load of students in educational activities have been studied as factors in the effectiveness of the educational process for a long time [1]. The study of behavioral strategies and cognitive features of first year students is essential [2]. Characteristic features of students majoring in psychology are manifested both in coping with the stress of the educational process [3] and in their professional skills [4].

Methods and Algorithms: There studied mistakes in the course of nonspecific cognitive activity (an analogue of educational activity) and in coping strategies of first year students majoring in psychology (group 1) and of first year students who study psychology majoring in nonpsychological subjects (group 2).

Results: It is shown that both groups do not differ statistically in intelligence, however, students from group 1 while performing cognitive activity make more mistakes than students from group $2(p<0.05) .37 .5 \%$ of group 1 have tiredness and $62.5 \%$ of group 1 have different types of fatigue. $31.1 \%$ of group 2 have work stress, $43.2 \%$ of group 2 have tiredness and $25.7 \%$ of group 2 have different types of fatigue. Group 2 uses all copying strategies except the emotionally-oriented strategy of "self-control" (<40T-score). Group 1 also uses all copying strategies but the most preferred (>60T-score) are the search for social support (problem-oriented) and positive re-evaluation (emotionallyoriented).

Conclusion: Coping strategies of small efficiency (emotionally-oriented ones) of the first year students go along with many their mistakes in cognitive activity. There is no one among the first year students majoring in psychology who has work stress (minimum state that is suitable for effective cognitive activity) - all students from group 1 have tiredness or different types of fatigue. Students majoring in psychology need additional courses to develop skills for effective coping with stress during the first year study.

\section{References}

1. Nikolaeva E.I. et al. (2013) Psychophysiological methods for assessing the effectiveness of the learning process. In: The quality of psychological education: the unity of theory and practice: a collective monograph. Novosibirsk. 203-217.

2. Nikolaeva E.I. et al. (2013) Psychophysiological fundamentals of adaptation of students-psychologists to educational activity. In: The quality of psychological education: the unity of theory and practice: a collective monograph. Novosibirsk. 218-250.

3. Nikolaeva E.I. et al. (2013) Some regularities in the regulation of the psychoemotional state in psychology students. In: The quality of psychological education: the unity of theory and practice: a collective monograph. Novosibirsk. 251-263.

4. Vergunov E.G. (2013) Quantitative approach to the estimation of students-psychologists' self-control competence. Psychology of education in a multicultural space. 3(23):30-35. 